\title{
Diagnosing the causes of territory abandonment by the Endangered Egyptian vulture Neophron percnopterus: the importance of traditional pastoralism and regional conservation
}

\author{
Patricia Mateo-Tomás and Pedro P. Olea
}

\begin{abstract}
Identifying threats to declining species and prescribing ways of preventing their extinction are basic challenges for biodiversity conservation. We analysed the causes underlying the loss of territories of the Endangered Egyptian vulture Neophron percnopterus in a key population at the north-western edge of its distribution in Europe by developing multi-scale models that combined factors from nest site to landscape. We used generalized linear models and an information-theoretic approach to identify the optimal combination of scales and resolutions that could explain territorial abandonment. Those models combining nest-site and landscape scales considerably improved prediction ability compared to those considering only one scale. The best combined model had a high predictive ability (96.9\% of correctly classified cases). Small cliffs at high altitudes in rugged areas with declining livestock (especially of sheep and goats) increased the likelihood of territory abandonment. Our findings highlight the importance of developing region-specific multi-scale models to determine reliably the factors driving territory loss and of designing effective conservation strategies accordingly. Conservation measures for the studied population should be developed at two spatial scales. At the smaller scale it is necessary to closely control nest sites to avoid direct disturbances. At a larger scale it is essential to implement policies that can support traditional pastoralism.
\end{abstract}

Keywords Egyptian vulture, extensive farming, informationtheoretic approach, livestock, model, multi-scale, Neophron percnopterus, territory abandonment

This paper contains supplementary material that can be found online at http://journals.cambridge.org

\section{Introduction}

$\mathrm{D}$ escribing which species are threatened, identifying the underlying mechanisms, and then prescribing

Patricia Mateo-Tomás (Corresponding author) Department of Biodiversity and Environmental Management, Faculty of Biological and Environmental Sciences, University of León, Campus de Vegazana, E-24071, León, Spain. E-mail pmatt@unileon.es

Pedro P. Olea School of Biology, IE University, Segovia, Spain

Received 27 September 2008. Revision requested 22 December 2008. Accepted 5 March 2009. ways of preventing extinctions are basic challenges for biodiversity conservation (Purvis et al., 2000). The Endangered Egyptian vulture Neophron percnopterus is a migratory, medium-sized raptor whose populations have recently declined throughout its range (IUCN, 2008). The causes driving this decline have been analysed in Italy (Liberatori \& Penteriani, 2001; Sarà \& Di Vittorio, 2003), Spain (Donázar et al., 2002; Carrete et al., 2007; Grande et al., 2009) and wintering areas in Africa (Grande et al., 2009). Factors involved in territory loss in Italy seem primarily related to human threats and reduction in food availability because of decreasing livestock density and/or changes in cattleraising practices (Liberatori \& Penteriani, 2001; Sarà \& Di Vittorio, 2003). In peninsular Spain poisoning, the species' social behaviour and habitat diversity are the most important predictors of territory loss at a landscape scale (Carrete et al., 2007). This information can help guide conservation of this species, for which Spain is one of the most important conservation strongholds (IUCN, 2008).

However, insufficient information is available for the management and conservation of the Egyptian vulture at local or regional levels. Lack of such information hinders geographically broad conservation schemes (McAlpine et al., 2008), and a species can be subject to varying risks of local extinction because of variability in threats across its range (Isaac \& Cowlishaw, 2004). These two situations may pertain to the Egyptian vulture in Spain, where the species is widely distributed in two bioclimatic regions, the Mediterranean and Euro-Siberian (north-west Spain), and displays differing regional population trends (García-Ripollés \& López-López, 2006; Carrete et al., 2007; Mateo-Tomás et al., 2010). Management measures generically recommended in Spain for Egyptian vulture conservation include conservation of communal roosts and rabbit Oryctolagus cuniculus populations (Donázar, 2004; Carrete et al., 2007). These measures are useful for some Mediterranean populations but not for Euro-Siberian populations, which do not depend on rabbits and do not use roosts regularly (P. Mateo-Tomás \& P.P. Olea, unpubl. data). Additionally, disturbance by human activities and wind farms have recently been identified as potentially affecting some Egyptian vulture populations (COCN et al., 2008; Zuberogoitia et al., 2008; Mateo-Tomás et al., 2010).

The study reported here focused on the Egyptian vulture population of the Cantabrian Mountains, which support 
c. $20 \%$ of the Spanish population (mostly within the EuroSiberian region; Mateo-Tomás et al., 2010). Given the global decline of the species, this area may become a key site for its conservation (Gärdenfors, 2001). However, despite the relative stability of this population compared to those in other areas of Spain (Carrete et al., 2007), a number of territories have been abandoned since 1997. Here we report our attempt to identify the causes of the abandonment of these territories, which we examined simultaneously at several scales, from nest site to landscape. We also provide recommendations, based on our findings, for management and conservation to prevent further loss of territories.

\section{Study area and species}

The study area is on the southern slope of the Cantabrian Mountains (Fig. 1), extending over $8,500 \mathrm{~km}^{2}$ within the EuroSiberian climatic region and a Euro-Siberian-Mediterranean transition zone running east-west. Extensive livestock farming (i.e. free-ranging cows, sheep and goats at low stocking densities), is the main rural activity. Most Egyptian vulture territories (75\%) are located within the Euro-Siberian region. Monitored nests were at altitudes of $670-1,575 \mathrm{~m}$.

The Egyptian vulture is a territorial, cliff-nesting raptor distributed from the Mediterranean to India and in Africa. The species is categorized as Endangered in Spain, which now holds the largest population (c. 1,40o breeding pairs) in the occidental Palearctic (Donázar, 2004). Breeding pairs arrive from their winter range in Africa in March and remain in their territories until mid September, rearing one or two chicks (Donázar, 1993). The same territory is generally used each year by a pair and is actively defended by its occupants (Donázar, 1993). Breeding dispersal is low (7.5\%), and thus territories probably become vacant because of the loss of territory owners without later recruitment, rather than because of territory change (Carrete et al., 2007). Although the species is relatively tolerant of human presence (Donázar, 2004) it is highly sensitive to poisoning (Grande et al., 2009).

\section{Methods}

\section{Conceptual model}

We designed a multi-scale conceptual model describing the factors influencing the persistence or abandonment of territories by Egyptian vultures (Fig. 2; Table 1). Three scales were considered (nest, cliff and landscape), defined according to species-habitat relationships potentially important for the species. Nest and nesting-cliff scales characterize the nest site, defining the basic reproductive requirements of a breeding pair (Liberatori \& Penteriani, 2001). At the landscape scale we considered three resolutions: a core area (i.e. the area actively defended by a breeding pair) and two home ranges (i.e. the area that is most intensively used by the pair, mainly for foraging; Donázar, 1993). The nest and cliff scales are the most important because, without a cliff with a suitable nest, the other scales would not be relevant. Therefore we modelled nest-site scales together with each of the landscape resolutions (Fig. 2).

\section{Surveys}

Egyptian vulture territories were located by a review of previous censuses (Del Moral \& Martí, 2002; F. Jubete, pers. comm.; authors, unpubl. data), interviews with local shepherds, and field surveys during 2005-2007. We located 80 territories that have been occupied by Egyptian vultures for at least 1 year during 1997-2007. Each territory was mapped using the geographical information system ArcGIS v. 9.o (ESRI, Redlands, USA). Our final dataset consisted of 50 occupied and 14 abandoned breeding territories that could provide data at the nest-site scale (Fig. 1). Egyptian vulture breeding pairs can use different nests in different years (Donázar, 1993) but such nests are

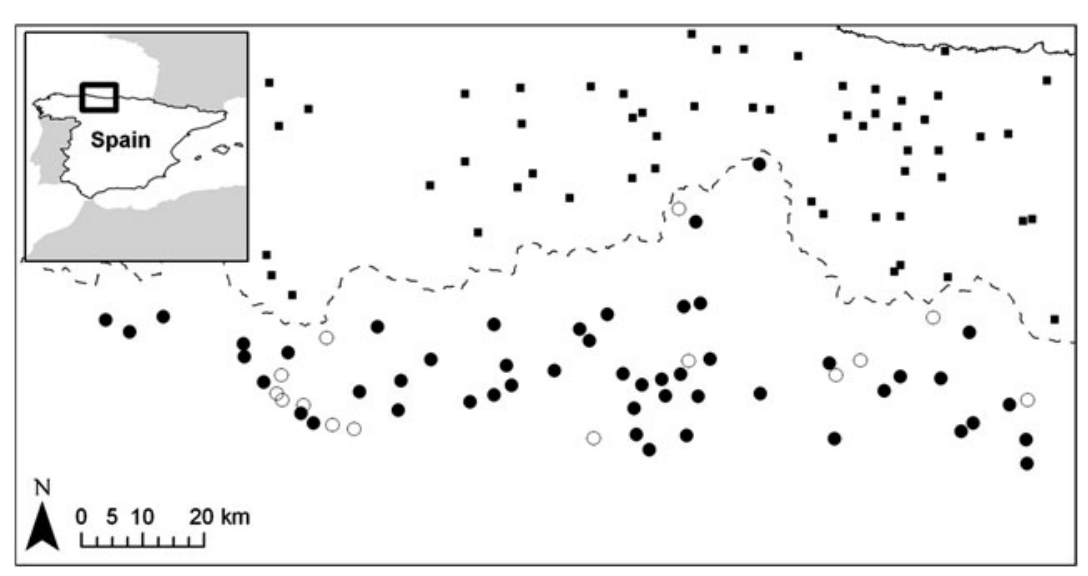

FIg. 1 Egyptian vulture territories, centred at the last nest known, in the study area and surroundings. Filled circles are occupied territories $(n=50)$ and unfilled circles are abandoned territories $(n=14)$. The dotted line shows the northern border of the study area; squares represent unmonitored territories. The rectangle on the inset indicates the position of the main map in northern Spain. 
NEST CLIFF
LANDSCAPE

Core Area and Home Range

(1 km)

(2.5 and $5 \mathrm{~km}$ )

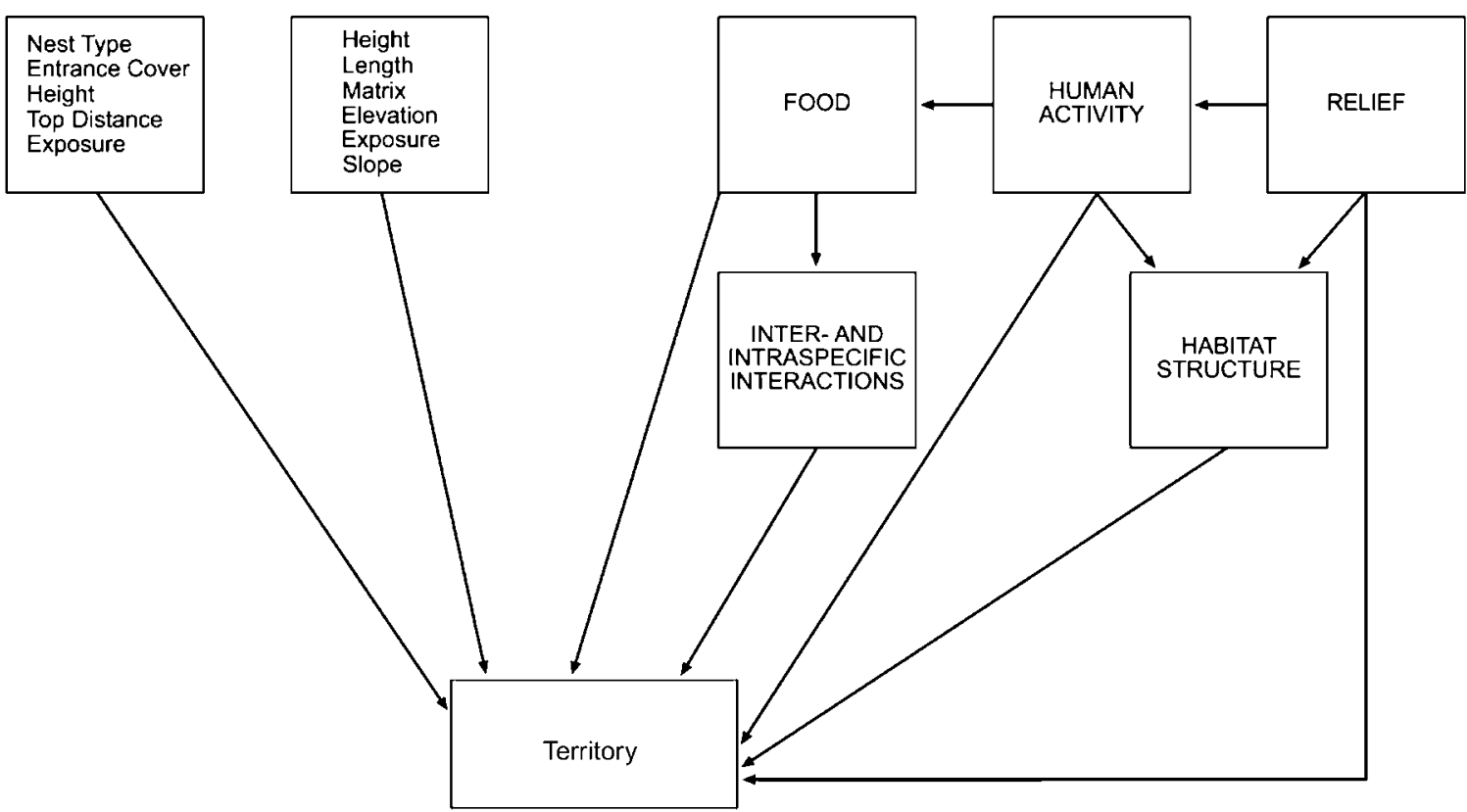

FIG. 2 Multi-scale conceptual model of the factors influencing the abandonment of a territory by the Egyptian vulture. This model considered three scales (i.e. nest, cliff and landscape) and three resolutions (i.e. 1-km core area, and 2.5- and 5-km home ranges; see text for details) at the landscape scale. For a description of all 36 variables see Table 1.

usually close to each other within the same territory (Zuberogoitia et al., 2008). Therefore, we considered a territory abandoned if it had been occupied for at least 1 year in 1997-1999 but we did not detect Egyptian vultures within the territory in 2005-2007. In our study area the Egyptian vulture has a relatively low detectability (the probability of detecting the species during a visit, if present $=0.44-0.49$; authors, unpubl. data). We visited the territories numerous times (mean $=6$ visits per territory per year, $\mathrm{n}=801$ visits) in 2005-2007 to confirm unequivocal occupation or abandonment (95\% confidence; authors, unpubl. data). The high quality of the data, especially for abandoned territories, allows accurate predictions despite the unbalanced dataset (JiménezValverde \& Lobo, 2006). Every visit consisted of the inspection of the territory on days with good visibility, using binoculars and telescopes.

\section{Explanatory variables}

We measured a set of variables of potential relevance for the species. Nest location and cliff were described according to morphological features (Table 1). Core area was considered to be the area within a $1-\mathrm{km}$ radius of a nest (Carrete et al., 2007). The home range resolutions considered were (1) a $2.5-\mathrm{km}$ radius around the nest (half the average nearest-neighbour distance between territories in the study area; Sarà \& Di Vittorio, 2003; authors, unpubl. data), and
(2) a $5-\mathrm{km}$ radius (double the nearest-neighbour distance, and the territory size recorded in similar areas; Bergier \& Cheylan, 1980). We measured 36 variables in five categories: habitat structure, relief, food, inter- and intraspecific interactions and human presence (see Table 1 for hypotheses). The variables were measured in the field or from aerial photographs and detailed maps, and validated by field observations. Because of the high sensitivity of the species to poisoning (Carrete et al., 2007) we considered poisoning events within the study area since 2000 . These data were obtained at the municipality level from the relevant environmental authorities. We derived three variables with regard to the species implicated in the poisoning event (i.e. mammals, birds or avian scavengers; Table 1) to account for the accessibility of vultures to poison. Climate variables were not included in the analysis because topographic characteristics better summarize microclimatic conditions at the local level (Austin, 2002). Feeding stations were not included because, in contrast to other regions (Carrete et al., 2007), there are no permanent feeding points in the study area. Similarly, no communal roosts have been reported in the study area (Carrete et al., 2007).

\section{Statistical analysis}

Linearity was explored by plotting generalized additive models (Hastie \& Tibshirani, 1990) of the response variable (i.e. persistence/abandonment, as 1/o) against every 
TABLE 1 The 36 variables describing nest-site and landscape characteristics considered potentially to explain territory abandonment by the Egyptian vulture Neophron percnopterus.

\begin{tabular}{lll}
\hline Variable (description) & Data source & Hypotheses \\
\hline $\begin{array}{l}\text { Nest } \\
\text { Nest Type (on ledge or inside cave) }\end{array}$ & Observation & $\begin{array}{l}\text { Presence of caves \& vegetation at entrance, \& nest } \\
\text { placed far from bottom or top of cliff, can provide } \\
\text { protection against inclement weather \&/or } \\
\text { predators }\end{array}$ \\
Entrance Cover (\% of nest entrance covered by & Observation &
\end{tabular}

vegetation)

Height (nest height from bottom of cliff, $\mathrm{m}$ )

Top Distance (distance from nest to top of cliff, $m$ )

Exposure (compass orientation of cliff at level of nest)

\section{Cliff}

Height (of nesting cliff, $\mathrm{m}$ )

Observation

Length (of nesting cliff, $\mathrm{m}$ )

Matrix (type of rock of nesting cliff)

Elevation (altitude of cliff, m)

Exposure (compass orientation of cliff)

Slope (degrees)

Aerial photographs

Observation

DEM $25 \mathrm{~m}^{1}$

Observation

DEM $25 \mathrm{~m}^{1}$
$\mathrm{S}$ or $\mathrm{E}$ exposures can provide protection against inclement weather

Larger cliffs \& erodable substrates can provide more nest sites, reducing likelihood of abandonment of cliff or territory

Lower elevation \& S or E exposures can provide protection against inclement weather

Steep cliffs can provide protection against predators

Landscape (all variables measured within radii of $1,2.5 \& 5 \mathrm{~km}$ around nest, except linear distances)

Relief

Mean slope (degrees)

Cliffs (total length of cliffs, m)

Habitat structure

Forest (\% of land covered by forest)

Shrub (\% of land covered by shrubs)

Rocky (\% of land covered by rock)

Pasture (\% of land covered by pasture)

Water (\% of surface covered by water)

Urban (\% of surface urbanized)

Patch (no. of landscape patches of any type)

Classes (no. of different landscape categories)

Diversity (habitat diversity calculated with

Shannon-Weaver index) ${ }^{3}$

Food

Livestock (no. of livestock units in year of survey) ${ }^{4}$

Cows (no. of cows in year of survey)

Sheep (no. of sheep \& goats in year of survey)

Inter- \& intra-specific interactions

Neighbour (linear distance between nest \& nearest other nest occupied in year of survey, $\mathrm{m}$ )

Vulture pairs (no. of griffon vulture breeding pairs in year of survey)

Human activity

Village (shortest distance to nearest village, $\mathrm{m}$ )
DEM $25 \mathrm{~m}^{1}$

Aerial photographs

Official data ${ }^{2}$

Official data ${ }^{2}$

Official data ${ }^{2}$

Official data ${ }^{2}$

Official data ${ }^{2}$

Official data ${ }^{2}$

Official data ${ }^{2}$

Official data ${ }^{2}$

Official data ${ }^{2}$

Official data ${ }^{5}$

Official data ${ }^{5}$

Official data ${ }^{5}$

Aerial photographs

Authors censuses

Aerial photographs
Irregular topography makes foraging more difficult \& energetically expensive

More cliffs provide more places to nest

Dense vegetation makes foraging more difficult

Open land facilitates foraging

Water reduces natural habitat for foraging Urbanization reduces natural habitat for foraging \& can disturb breeding territories

Fragmented habitat makes foraging more difficult More diverse areas can provide more diverse sources of food

Livestock is a food resource

Presence of conspecifics can facilitate establishment of other breeding pairs but can also increase intraspecific competition for resources Presence of other scavenger species with similar ecology can increase interspecific competition for resources

Proximity to human populations can increase disturbance to breeding territories but can also provide predictable sources of food 
TABLE 1 (Continued)

\begin{tabular}{|c|c|c|}
\hline Variable (description) & Data source & Hypotheses \\
\hline Inhabitants (no. of inhabitants in year of survey) & Official data ${ }^{6}$ & $\begin{array}{l}\text { Presence of humans can increase disturbance in } \\
\text { breeding territories }\end{array}$ \\
\hline $\begin{array}{l}\text { Road (shortest linear distance to nearest paved } \\
\text { road, } \mathrm{m} \text { ) }\end{array}$ & Aerial photographs & \\
\hline $\begin{array}{l}\text { Dirt road (shortest linear distance to nearest unpaved } \\
\text { road, } \mathrm{m} \text { ) }\end{array}$ & Aerial photographs & \\
\hline Road density (density of paved roads, $\mathrm{m}$ ) & Aerial photographs & \\
\hline Dirt road density (density of unpaved roads, $\mathrm{m}$ ) & Aerial photographs & \\
\hline $\begin{array}{l}\text { POI (Frequency of poisoning events resulting in } \\
\text { death of some animal species, i.e. mammals, birds, } \\
\text { during study period) }\end{array}$ & Official data ${ }^{5}$ & $\begin{array}{l}\text { Poison increases mortality of adults \& young, } \\
\text { accelerating loss of territory }\end{array}$ \\
\hline $\begin{array}{l}\text { POIB (Frequency of poisoning events resulting in } \\
\text { death of some bird species, i.e. corvids, raptors, } \\
\text { during study period) }\end{array}$ & Official data ${ }^{5}$ & \\
\hline $\begin{array}{l}\text { POIS (Frequency of poisoning events resulted in } \\
\text { death of some avian scavengers, i.e. vultures, kites, } \\
\text { during study period) }\end{array}$ & Official data ${ }^{5}$ & \\
\hline
\end{tabular}

${ }^{1}$ Digital Elevation Model

${ }^{2} 3$ rd Spanish Forest Inventory, Ministerio de Medio Ambiente

${ }^{3}-\sum \mathrm{p}_{\mathrm{i}} \log \mathrm{p}_{\mathrm{i}}$, where $\mathrm{p}_{\mathrm{i}}=$ percentage of surface covered by habitat $\mathrm{i}$

${ }^{4} 1$ cow $=5$ livestock units; 1 sheep or goat $=1$ livestock unit

${ }^{5}$ Statistical service of Junta de Castilla y León in León and Palencia

${ }^{6}$ National Statistics Institute

explanatory variable (Table 1 ). After visual inspection of the resultant plots non-linear relationships were converted into two-piece linear effects by piece-wise regression, in which the explanatory variable is partitioned into intervals and a different linear function is fitted to each interval (Crawley, 2007). The optimal threshold, or the best position of the breakpoint, was selected according to the lowest residual deviance (Crawley, 2007). We used generalized linear models (GLMs) with a binomial error structure to identify those factors influencing territory abandonment.

Models were fitted independently for each scale by performing all possible model permutations (i.e. 8-64 models) of the explanatory variables. Each one of the five variable categories was first modelled independently for each landscape resolution. The models obtained for each scale and category were ranked using the corrected Akaike's Information Criterion (AICc) and the Akaike weight of each model $\left(\omega_{\mathrm{m}}\right)$, estimated according to Burnham \& Anderson (2002). We constructed a 95\% confidence set of models by starting with the highest Akaike weight and adding the model with the next highest weight until the cumulative sum of the weights exceeded 0.95 (Burnham \& Anderson, 2002). A model-filtering procedure was then applied according to Richards (2008). We obtained the best models for each scale, as well as for each category and resolution at the landscape scale. The explanatory variables from the best models (95\%) at nest and cliff scale were combined to obtain the best nest-site models by following the same procedure described above. Likewise, at the landscape scale, the explanatory variables from the best models in each category were combined to obtain the best core area and home range models (resolution-specific models).

Finally, the explanatory variables at the nest-site scale were combined with those obtained from each landscape resolution, yielding three final combined models. This procedure allowed us to determine which scale or scale combination best explained the occurrence of the Egyptian vulture by comparing AICc values and the explained deviance of the models. We performed a model averaging approach. Unconditional coefficients for each variable were estimated from all combined models within 95\% probability, weighted by $\omega_{\mathrm{i}}$ (Burnham \& Anderson, 2002), and resulting in averaged combined models. To ascertain the relative contribution of each variable in the averaged combined models we calculated their Akaike weight (Burnham \& Anderson, 2002). The variables with the highest weight $\left(\Sigma \omega_{\mathrm{i}}\right)$ were more important relative to the others. A hierarchical partitioning analysis was also performed to determine the independent and joint contribution of each variable to the total explanatory power of the model (MacNally, 2002). Interactions of variables included in the final models were also assessed.

From highly inter-correlated variable pairs (Spearman correlation coefficient, $\left|r_{s}\right|>0.5$ ), we selected those variables with both the highest independent contribution to the response variable according to a hierarchical partitioning procedure and the highest deviance according to univariate 
GLMs performed for each explanatory variable. Models were not overdispersed (Lindsey, 1999). Spatial correlation was assessed in the response variables and residuals of the complete models by inspection of a semivariogram function (gamma; Olea, 2009).

Although model evaluation should involve a comparison with independent data, in studies involving rare species and small extents such a dataset is not always available (Gibson et al., 2004), as was the case here. The discrimination ability of each complete model was assessed using the area under the receiver operating characteristic curve (Pearce \& Ferrier, 2000). Although there are drawbacks to this method an alternative is to use the area under the receiver operating characteristic curve together with specificity and sensitivity when comparing models for the same species in the same area (Lobo et al., 2008). The correct classification rate $(r=$ number of sites correctly classified/total number of sites) was also calculated. The thresholds above which the species was considered to be present were established by maximizing the sum of sensitivity and specificity (Liu et al., 2005). All the analyses were performed with $R$ v. 2.7.2 (R Development Core Team, 2008).

\section{Results}

At the nest scale no models were better than the null model (i.e. with intercept only; Appendix 1). At the cliff scale, the best models showed that the probability of abandoning a territory increased on narrower cliffs at high elevation. The best models at the landscape scale demonstrated the positive influence of livestock on territory persistence at all the resolutions considered. The abundance of rocky cliffs also had a strong positive influence on territory permanence. The probability of territory abandonment decreased with high landscape heterogeneity at a $1-\mathrm{km}$ radius and low topographic irregularity at a $2.5-\mathrm{km}$ radius.

The combination of the most important variables at nest, cliff and landscape scales yielded combined models that were much better than resolution-specific models with regard to both deviance and AIC (Table 2; Appendix 2). The best results were obtained at a $2.5-\mathrm{km}$ radius, with the best combined model $\left(\omega_{\mathrm{m}}=0.85\right)$ explaining $83.97 \%$ of deviance (Table 2).

The three averaged combined models included cliff length and elevation together with livestock, landscape heterogeneity and topography-related variables (Table 3). Landscape heterogeneity favoured territorial persistence at core-area resolution. Livestock was the most important factor influencing territorial persistence at $1-$ and $5-\mathrm{km}$ radii (Fig. 3). The abundance of cows and sheep at $2.5 \mathrm{~km}$ was significant for territory maintenance. The probability of territory abandonment at a $2.5-\mathrm{km}$ resolution decreased with both increasing numbers of cliffs and decreasing slope. Rocky surface was a predictor of Egyptian vulture persis- tence at $5 \mathrm{~km}$. Because the best $2.5 \mathrm{~km}$ combined model had a high weight it was also considered among the best final models (Table 2). The best $2.5 \mathrm{-km}$ combined model included the same variables as the $2.5-\mathrm{km}$ averaged combined model, except for cliff length (Table 3 ).

No significant effect of spatial autocorrelation was detected in the final averaged combined models. These three models had good discrimination ability, as indicated by the area under the receiver operating characteristic curve and the correct classification rates (Table 2). Overall, the $2.5-\mathrm{km}$ averaged combined model was the best averaging model predicting territory abandonment (proportion of abandoned territories correctly classified $r_{a}=0.86$ vs 0.64 and 0.57 for $5-\mathrm{km}$ and $1-\mathrm{km}$ averaged combined models, respectively). Nonetheless, the best $2.5-\mathrm{km}$ combined model was better in predicting territory abandonment $\left(\mathrm{r}_{\mathrm{a}}=0.93\right)$.

Among the variables included in averaged combined models, livestock was the only one that could have changed significantly during 1997-2007 and hence influenced territory loss. While the cow population increased $22 \%$ during 1997-2005, sheep and goats decreased significantly (29\%; Fig. 4). The increase in the cow population was larger in abandoned Egyptian vulture territories than in occupied territories (56\% vs $16 \%)$. However, there were still more cows in occupied than in abandoned territories in 2005 (mean $2,350 \pm$ SE 208 vs $1,922 \pm 352$ ). Moreover, during 1997-2005 abandoned territories exhibited a larger decrease in the numbers of sheep and goats than occupied territories ( $41 \%$ vs $26 \% ; \chi^{2}=806.8, \mathrm{df}=1, \mathrm{P}<0.001$; Fig. 4 ).

\section{Discussion}

Factors affecting territory abandonment by the Egyptian vulture

Abandoned territories of the Egyptian vulture were found at high elevations on narrow cliffs in rocky areas with fewer sheep and goats than the occupied territories. Both cliff length and elevation were the only factors from smaller scales selected by the three final averaged combined models (Table 3). Elevation could affect territory quality through weather conditions that, in the study area, are more adverse at higher altitudes. This contrasts with Mediterranean areas, where weather conditions are less adverse and higher elevations are preferred by the species (Liberatori \& Penteriani, 2001). The positive effect of greater cliff length in territory conservation has also been noted in other regions (Liberatori \& Penteriani, 2001). This effect may be related to competition with other cliff-nesters and to presence of predators or occurrence of human disturbance, all of which could be greater on smaller cliffs because of a lower availability of nest sites and greater accessibility for humans and terrestrial predators. In addition, the low availability on narrow cliffs of alternative sites to locate 
TABLE 2 Corrected Akaike's Information Criterion (AICc), percentage of deviance explained, percentage of correctly classified cases and discrimination ability (i.e. area under the curve) of the best $\left(\Sigma \omega_{\mathrm{m}}=0.95\right)$ combined and resolution-specific models at the three landscape resolutions (1-, 2.5- and 5-km radii, see text for details).

\begin{tabular}{lllll}
\hline Model type (by resolution) & AICc & \% deviance explained & \% correctly classified cases & Discrimination ability \\
\hline Core area $(\mathbf{1 ~ k m )}$ & & & & 0.723 \\
Combined & $59.22-65.71$ & $12.21-25.37$ & $87.5 \%$ & 0.714 \\
Resolution-specific & $61.24-67.55$ & $6.08-22.35$ & $85.9 \%$ & 0.873 \\
Home range $(\mathbf{2 . 5} \mathbf{~ k m})$ & & & $96.9 \%$ & 0.866 \\
Combined & $24.78-30.25$ & $75.83-83.97$ & $90.6 \%$ & \\
Resolution-specific & $39.88-44.94$ & $59.31-66.84$ & & 0.744 \\
Home range $\mathbf{5} \mathbf{~ k m})$ & & & $89.1 \%$ & 0.709 \\
Combined & $57.07-60.72$ & $19.96-35.95$ & $82.8 \%$ & \\
Resolution-specific & $82.23-84.15$ & $11.76-19.96$ & \\
\hline
\end{tabular}

a nest could increase the probability of abandonment. The $1-\mathrm{km}$ averaged combined model retained landscape heterogeneity as a factor positively influencing territory persistence, and landscape heterogeneity has been found to be related to food availability at the national level (Carrete et al., 2007). The $2.5-\mathrm{km}$ averaged combined model also retained topographic irregularity, which could make foraging activity difficult and energetically costly (Bergier \& Cheylan, 1980).

TABLE 3 Averaged regression coefficients of the explanatory variables (see Table 1 for details) included in the averaged combined models for each landscape resolution (i.e. 1-, 2.5- and $5-\mathrm{km}$ radii, see text for details), and for the best $2.5-\mathrm{km}$ combined model $\left(\omega_{\mathrm{m}}=0.85\right)$

\begin{tabular}{|c|c|}
\hline Model & $\begin{array}{l}\text { Averaged regression } \\
\text { coefficients } \pm \text { SE }\end{array}$ \\
\hline \multicolumn{2}{|c|}{ Core Area $(1 \mathrm{~km})$} \\
\hline Livestock & $0.109 \pm 0.041$ \\
\hline Length & $0.003 \pm 0.001$ \\
\hline Classes & $0.321 \pm 0.175$ \\
\hline Elevation & $-0.001 \pm 0.000$ \\
\hline \multicolumn{2}{|c|}{ Home range $(2.5 \mathrm{~km})$} \\
\hline Slope & $-0.936 \pm 0.610$ \\
\hline Cows & $0.815 \pm 0.591$ \\
\hline Cliffs & $0.002 \pm 0.001$ \\
\hline Length & $0.001 \pm 0.001$ \\
\hline Elevation & $-0.017 \pm 0.009$ \\
\hline Sheep & $0.532 \pm 0.336$ \\
\hline \multicolumn{2}{|c|}{ Best $2.5-\mathrm{km}$ combined model $\left(\omega_{\mathrm{m}}=0.85\right)$} \\
\hline Slope & $-0.985 \pm 0.665$ \\
\hline Cows & $0.869 \pm 0.655$ \\
\hline Cliffs & $0.002 \pm 0.001$ \\
\hline Elevation & $-0.019 \pm 0.010$ \\
\hline Sheep & $0.594 \pm 0.378$ \\
\hline \multicolumn{2}{|c|}{ Home range $(5 \mathrm{~km})$} \\
\hline Cows & $0.130 \pm 0.049$ \\
\hline Length & $0.002 \pm 0.001$ \\
\hline Sheep & $0.070 \pm 0.043$ \\
\hline Elevation & $-0.003 \pm 0.001$ \\
\hline Rocky & $7.018 \pm 4.871$ \\
\hline
\end{tabular}

The positive influence of livestock at all landscape resolutions considered could be explained by its role as a fundamental trophic resource for the Egyptian vulture (Bergier \& Cheylan, 1980). As there are no feeding stations in the area, livestock seem to play a key role in the species' persistence, an association that is largely absent in other regions (Bergier \& Cheylan, 1980; Liberatori \& Penteriani, 2001). Although sanitary regulations because of bovine spongiform encephalopathy require the removal of livestock carcasses, these regulations are more relaxed for sheep and goats and in mountain areas with difficult access, as in our study area (Olea \& Mateo-Tomás, 2009). The importance of sheep and goats for Egyptian vultures (Sarà \& Di Vittorio, 2003) was also observed to influence territory persistence in our study area (Fig. 4). While the presence of cows positively influenced territory persistence up to a maximum threshold of 8.9 cows $\mathrm{km}^{-2}$, the probability of territory abandonment steadily decreased when numbers of sheep and goats increased. The greater decrease of sheep and goat populations in abandoned territories (Fig. 4) indicates the role of small livestock in the observed patterns of territory losses.

The incorporation of variables from smaller scales considerably improved the prediction ability of the combined models (Table 2), showing that nest-site scales should also be considered when designing conservation actions for the Egyptian vulture. Our approach allowed us to select the best resolution to predict territory abandonment. Accordingly, the best results were obtained at a $2.5-\mathrm{km}$ radius, corresponding to half the average nearest-neighbour distance in our study area. This stresses the importance of regional analysis to determine reliably the factors driving species extinction. The factors retained by our averaged combined models differ from those favouring territory persistence at the national scale (Carrete et al., 2007), underscoring the importance of region-specific management to complement general conservation guidelines (McAlpine et al., 2008).

\section{Conservation implications}

There is an urgent need for the design of an effective management plan for the Egyptian vulture, given the Endangered 
(a) $1-\mathrm{km}$ radius

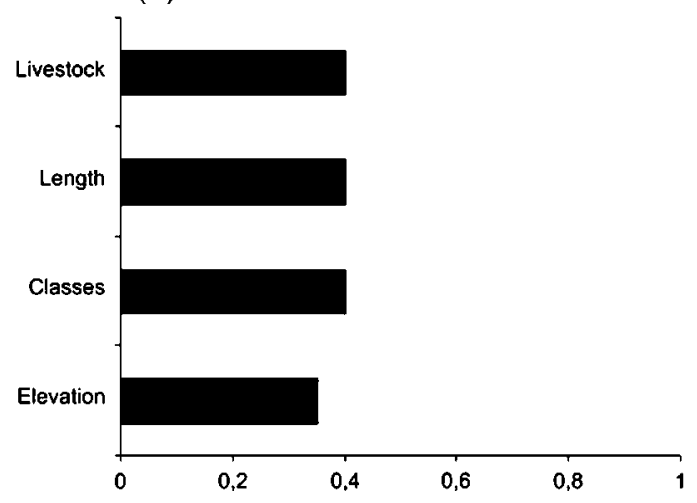

(b) $2.5-\mathrm{km}$ radius

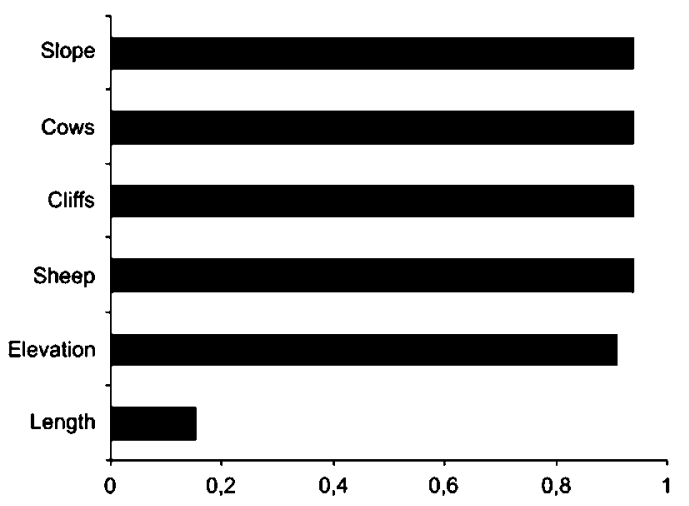

(c) $5-\mathrm{km}$ radius

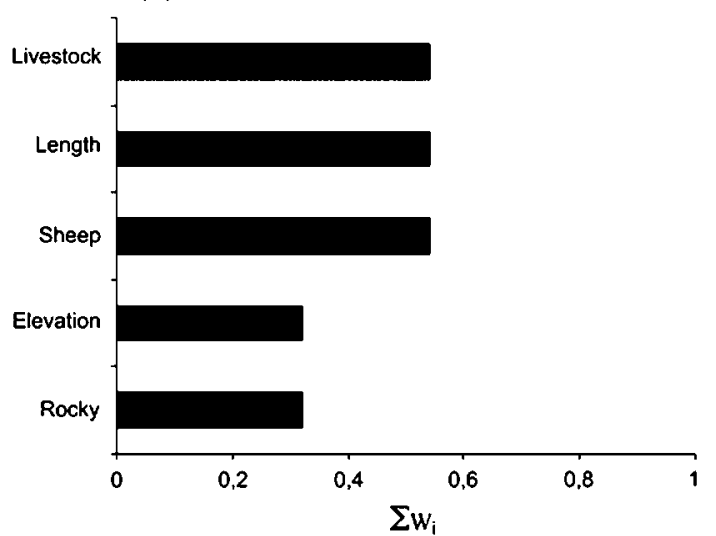

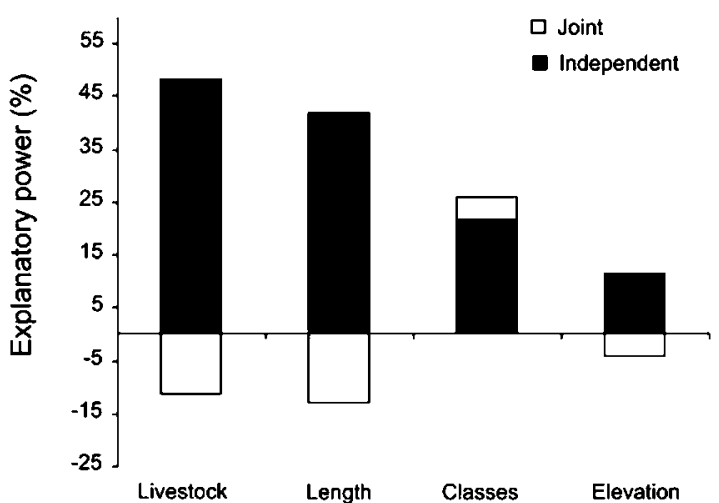
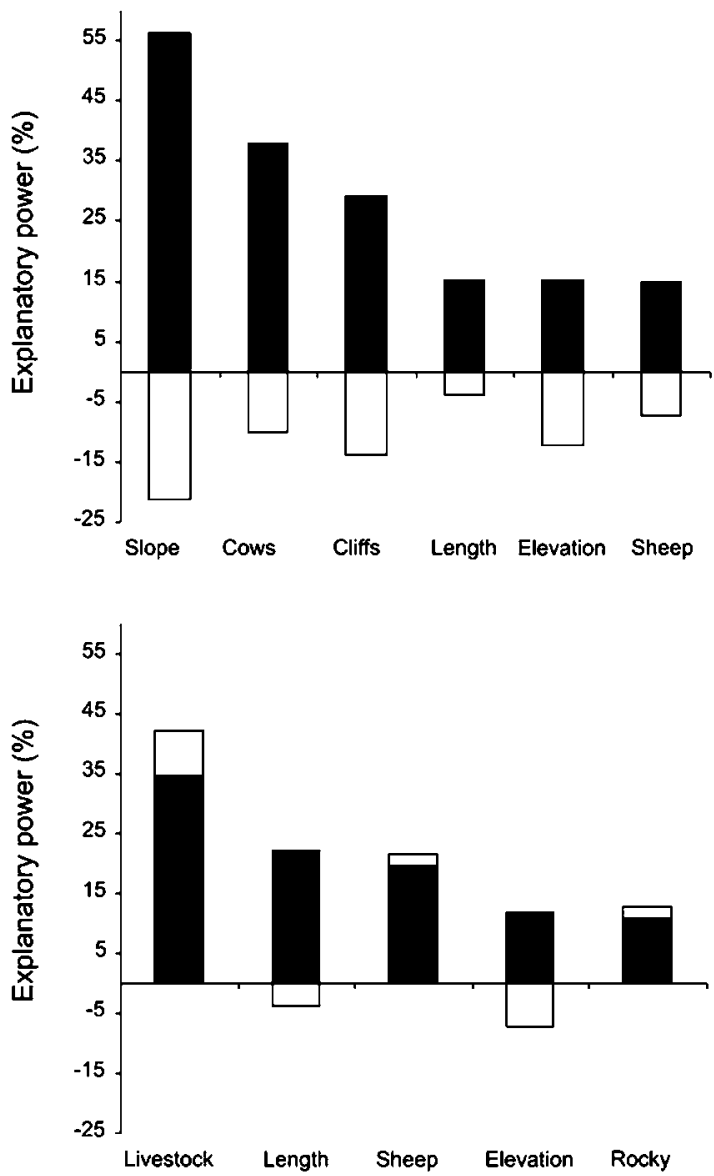

FIG. 3 Ranking of importance of explanatory variables included in the best averaged combined models that combine nest, cliff and landscape scales with landscape at three resolutions: (a) $1-\mathrm{km}$ radius (core area), (b) $2.5-\mathrm{km}$ and (c) $5-\mathrm{km}$ radii around the nest (see text for details). Variable importance is represented by both the sum of their Akaike weights $\left(\Sigma \omega_{\mathrm{i}}\right.$; left) and the percentage of independent and joint contribution to the total explanatory power (hierarchical partitioning analysis; right).

categorization of the species worldwide (IUCN, 2008). In our study area in the Cantabrian Mountains the importance of small-scale variables indicates the need to control nest sites closely to avoid disturbances that could lead to movement of breeding pairs to suboptimal cliffs, where the probability of abandonment increases. The efficacy of such action has been demonstrated in other areas (Sarà \& Di Vittorio, 2003). Important human threats such as poison or habitat degradation, which have a detrimental impact in other regions
(Carrete et al., 2007), do not seem to influence territory abandonment in the Cantabrian Mountains (Table 3). However, the difficulty of obtaining accurate measurements of poisoning (Grande et al., 2009) and its delayed effects on populations (Oro et al., 2008) could hide greater effects.

At the landscape scale conservation measures that promote extensive livestock farming are required in the study area. Although correlational, our study detected an important potential underlying cause of the territory loss 

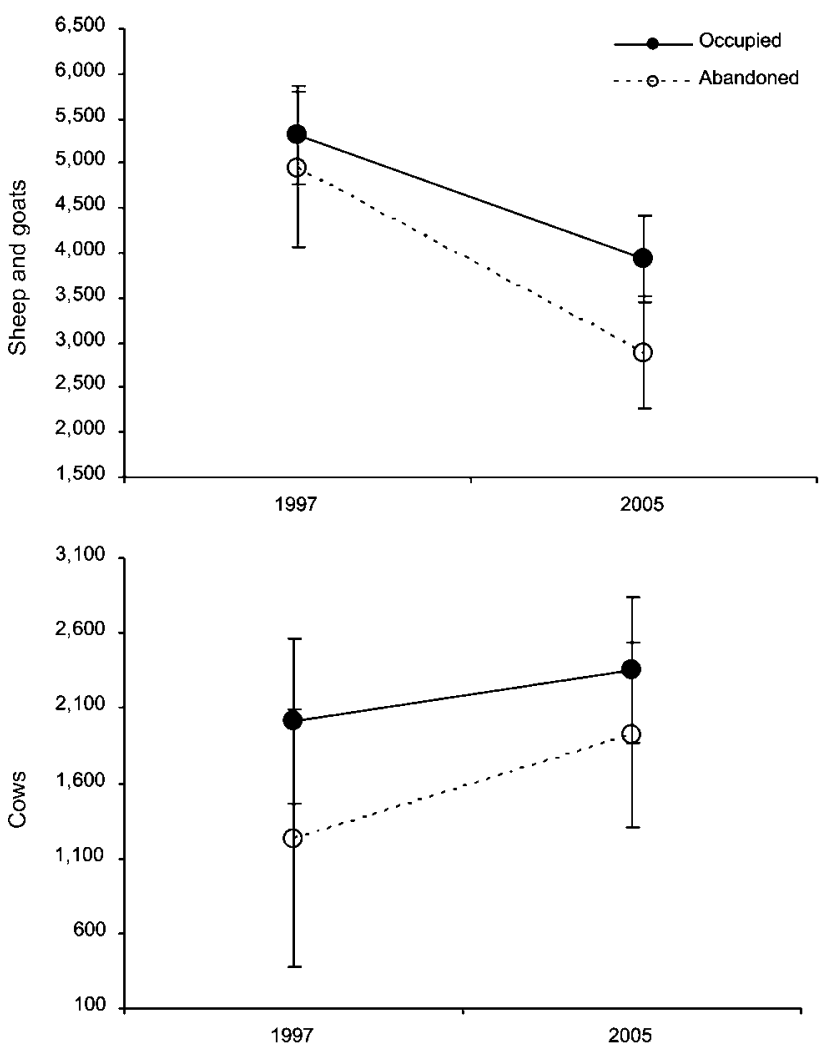

FIG. 4 Numbers of livestock in 1997-1999 and 2005-2007 in the municipalities that overlap with the $2.5-\mathrm{km}$ home range of the Egyptian vulture territories occupied and abandoned in the study area. Similar results were obtained for 1 - and $5-\mathrm{km}$ resolutions.

(i.e. a strong decrease in the numbers of sheep and goats). The key role that sheep and goats seem to be playing in Egyptian vulture conservation, through maintenance of territories, requires conservation planning specific to this area. The threats derived from changes in livestock can act slowly, compared to others such as poison, but their consequences can be irreversible, profoundly affecting not only the Egyptian vulture but the whole ecosystem. Feeding stations have been frequently recommended in other regions, where researchers have detected a significant influence of livestock on Egyptian vulture conservation (Sarà \& Di Vittorio, 2003). Although feeding stations are easy to implement they are only partial solutions, with negative longterm consequences for the species and ecosystem (Lemus et al., 2008; Oro et al., 2008).

The importance, demonstrated by our results, of extensive livestock farming for conservation of the Egyptian vulture is another example of the fundamental role that traditional farming activities can play in ecosystem conservation (Olea \& Mateo-Tomás, 2009). Policies are required that allow the maintenance of these low-impact human activities.

\section{Acknowledgements}

We thank J.C. del Moral for providing access to the 2nd Spanish Survey of Egyptian Vulture and F. Jubete and J. Placer for providing information about nesting locations. Junta de Castilla y León provided data on poisoning. J. Tomás, J. and J.A. Herrero, M. Gordaliza, F. Carcedo and J. Fernandez provided field assistance. Two anonymous reviewers provided useful comments. PMT was supported by a PhD scholarship of the Spanish Ministerio de Educación y Ciencia. IE University partially funded this study.

\section{References}

Austin, M.P. (2002) Spatial prediction of species distribution: an interface between ecological theory and statistical modelling. Ecological Modelling, 157, 101-118.

Bergier, P. \& Cheylan, G. (1980) Statut, succès de reproduction et alimentation du vautour pernoptére Neophron percnopterus en France Mediterranéenne. Alauda, 48, 75-97.

Burnham, K.P. \& Anderson, D.R. (2002) Model Selection and Multimodel Inference: A Practical Information-theoretical Approach. Springer-Verlag, New York, USA.

Carrete, M., Grande, J.M., Tella, J.L., Sánchez-Zapata, J.A., Donázar, J.A., Diaz-Delgado, R. \& Romo, A. (2007) Habitat, human pressure, and social behavior: partialling out factors affecting large-scale territory extinction in an endangered vulture. Biological Conservation, 136, 143-154.

CoCN (Colectivo Ornitológico Cigüeña Negra), Donázar, J.A., Carrete, M., de la Riva, M.J. \& Sánchez-Zapata, J.A. (2008) Muertes de alimoche en parque eólicos del estrecho de Gibraltar. Quercus, 273, 60-61.

Crawley, M.J. (2007) The R Book. John Wiley and Sons, Chichester, UK.

Del Moral, J.C. \& Martí, R. (2002) El alimoche común en España y Portugal. I Censo Coordinado. Año 200o. Monografía $n^{\circ}$ 8. SEO/ BirdLife, Madrid, Spain.

DonÁzAr, J.A. (1993) Los buitres ibéricos. Biología y conservación. Edicions Reyero, Madrid, Spain.

Donázar, J.A. (2004) Alimoche Común Neophron percnopterus. In Libro Rojo de las Aves de España (eds A. Madroño, C. Gonzalez \& J.C. Atienza), pp. 166-167. Dirección General para la BiodiversidadSEO/Birdlife, Madrid, Spain.

Donázar, J.A., Palacios, C.J., Gangoso, L., Ceballos, O., GonzÁlez, M.J. \& Hiraldo, F. (2002) Conservation status and limiting factors in the endangered population of Egyptian vulture (Neophron percnopterus) in the Canary Islands. Biological Conservation, 107, 89-97.

García - Ripollés, C. \& López-López, P. (2006) Population size and breeding performance of Egyptian vultures (Neophron percnopterus) in eastern Iberian Peninsula. Journal of Raptor Research, $40,217-221$.

GÄRDENFORS, U. (2001) Classifying threatened species at national versus global levels. Trends in Ecology \& Evolution, 16, 511-516.

Gibson, L.A., Wilson, B.A., Cahill, D.M. \& Hill, J. (2004) Spatial prediction of rufous bristlebird habitat in a coastal heathland: a GIS-based approach. Journal of Applied Ecology, 41, 213-223.

Grande, J.M., Serrano, D., Tavecchia, G., Carrete, M., Ceballo, O., Díaz-Delgado, R. et al. (2009) Survival in a long-lived territorial migrant: effects of life-history traits and ecological conditions in wintering and breeding areas. Oikos, 118, 580-590. 
Hastie, T.J. \& Tibshirani, R.J. (1990) Generalized Additive Models. Chapman and Hall, New York, USA.

Isaac, N.J.B. \& Cowlishaw, G. (2004) How species respond to multiple extinction threats. Proceedings of the Royal Society of London Series B, 271, 1135-1141.

IUCN (2008) 2008 IUCN Red List of Threatened Species. IUCN, Gland, Switzerland. Http://www.iucnredlist.org [accessed 13 July 2009].

Jiménez-Valverde, A. \& Lobo, J.M. (2006) The ghost of unbalanced species distribution data in geographical model predictions. Diversity and Distributions, 12, 521-524.

Lemus, J.A., Blanco, G., Grande, J., Arroyo, B., GarcíaMontijano, M. \& Martínez, F. (2008) Antibiotics threaten wildlife: circulating quinolone residues and disease in avian scavengers. PLoS ONE, 3(1): e1444.

Liberatori, F. \& Penteriani, V. (2001) A long-term analysis of the declining population of the Egyptian vulture in the Italian peninsula: distribution, habitat preference, productivity and conservation implications. Biological Conservation, 101, 381-389.

LINDSEY, J.K. (1999) On the use of corrections for overdispersion. Journal of the Royal Statistical Society, Series C, Applied Statistics, $48,553-561$.

Liu, C., Berry, P.M., Dawson, T.P. \& Pearson, R.G. (2005) Selecting thresholds of occurrence in the prediction of species distributions. Ecography, 28, 385-393.

Lobo, J.M., Jiménez-Valverde, A. \& Real, R. (2008) AUC: a misleading measure of the performance of predictive distribution models. Global Ecology and Biogeography, 17, 145-151.

MacNally, R. (2002) Multiple regression and inference in ecology and conservation biology: further comments on identifying important predictor variables. Biodiversity and Conservation, 11, 1397-1401.

McAlpine, C.A., Rhodes, J.R., Bowen, M.E., Lunney, D., Callaghan, J.G., Mitchell, D.L. \& Possingham, H.P. (2008) Can multiscale models of species' distribution be generalized from region to region? A case study of the koala. Journal of Applied Ecology, 45, 558-567.

Mateo-Tomás, P., Olea, P.P. \& Fombellida, I. (2010) Status, trend and threats of the Endangered Egyptian vulture Neophron percnopterus in the west of the Cantabrian Mountains. Oryx, 44, in press.
OleA, P.P. (2009) Analysing spatial and temporal variation in colony size: an approach using autoregressive mixed models and information theory. Population Ecology, 51, 161-174.

Olea, P.P. \& MAтеo-Tomás, P. (2009) The role of traditional farming practices in ecosystem conservation: the case of transhumance and vultures. Biological Conservation, 142, 1844-1853.

Oro, D., Margalida, A., Carrete, M., Heredia, R. \& Donazar, J.A. (2008) Testing the goodness of supplementary feeding to enhance population viability in an endangered vulture. PLOS ONE, 3(12), e4084.

Pearce, J. \& Ferrier, S. (2000) Evaluating the predictive performance of habitat models developed using logistic regression. Ecological Modelling, 133, 225-245.

Purvis, A., Gittleman, J.L., Cowlishaw, G. \& Mace, G.M. (2000) Predicting extinction risk in declining species. Proceedings of the Royal Society of London Series B, 267, 1947-1952.

R Development Core Team (2008) R: A Language and Environment for Statistical Computing. R Foundation for Statistical Computing, Vienna, Austria. Http://www.R-project.org [accessed 13 July 2009].

RICHARDS, S.A. (2008) Dealing with overdispersed count data in applied ecology. Journal of Applied Ecology, 45, 218-227.

Sarè, M. \& Di Vittorio, M. (2003) Factors influencing the distribution, abundance and nest-site selection of an endangered Egyptian vulture (Neophron percnopterus) population in Sicily. Animal Conservation, 6, 317-328.

Zuberogoitia, I., Zabala, J., Martínez, J. \& Azcona, A. (2008) Effect of human activities on Egyptian vulture breeding success. Animal Conservation, 11, 313-320.

\section{Appendix}

The appendix for this article is available online at http:// journals.cambridge.org

\section{Biographical sketches}

Patricia Mateo-Tomás researches the conservation and management of vultures and is currently studying the impacts of traditional human activities on the conservation of biodiversity. Pedro P. Olea carries out conservation biology research with a particular interest in birds. He is currently leading a multidisciplinary team focused on biodiversity conservation, analysing the impact of human activities on ecosystem conservation. 